\title{
Hyporheic Exchange Controls Fate of Trace Organic Compounds in an Urban Stream
}

Jonas Schaper (1) https://orcid.org/0000-0002-5526-3743, Malte Posslet (1) https://orcid.org/0000-0001-89798044, James L. MacCallum, Eddie W. Banks (1) https://orcid.org/0000-0002-2431-7649, Anja Hoehne, Karin Meinikmann, Margaret A. Shanafield (1) https://orcid.org/0000-0003-1710-1548, Okke Batelaan, and Joerg Lewandowski

DOI

10.1021/acs.est.8b03117

Original publication date

7 October 2018 (Available online)

Document version

Accepted manuscript

Published in

Environmental Science and Technology

\section{Citation}

Schaper JL, Posselt M, McCallum JL, Banks EW, Hoehne A, Meinikmann K, Shanafield MA, Batelaan O, Lewandowski J. Hyporheic Exchange Controls Fate of Trace Organic Compounds in an Urban Stream. Environ Sci Technol. 2018;52(21):12285-94. 


\section{Hyporheic exchange controls fate of trace organic compounds in an 2 urban stream}

3 Jonas L. Schaper* ${ }^{1,2}$, Malte Posselt ${ }^{3}$, James L. McCallum ${ }^{4}$, Eddie W. Banks ${ }^{4}$, Anja Hoehne ${ }^{2}$, Karin Meinikmann ${ }^{1}$,

4 Margaret A. Shanafield ${ }^{4}$, OKke BatelaAn ${ }^{4}$, AND Joerg LeWandowski ${ }^{1,5}$

5

$6{ }^{1}$ Leibniz-Institute of Freshwater Ecology and Inland Fisheries, Department Ecohydrology, Müggelseedamm 310,

$7 \quad 12587$ Berlin, Germany

$8{ }^{2}$ Technical University of Berlin, Chair of Water Quality Engineering, Strasse des 17. Juni 135, 10623 Berlin,

9 Germany

$10{ }^{3}$ Department of Environmental Science and Analytical Chemistry (ACES), Stockholm University, Stockholm,

11 Sweden

$12{ }^{4}$ National Centre for Groundwater Research and Training, College of Science and Engineering, Flinders University,

13 GPO Box 2100, Adelaide 5001, South Australia, Australia

$14 \quad{ }^{5}$ Humboldt University Berlin, Geography Department, Rudower Chaussee 16, 12489 Berlin, Germany

15

$16 *$ *orresponding author; schaper@igb-berlin.de, Leibniz-Institute of Freshwater Ecology and Inland Fisheries,

17 Department Ecohydrology, Müggelseedamm 310, 12587 Berlin, Germany 


\section{TOC Art}

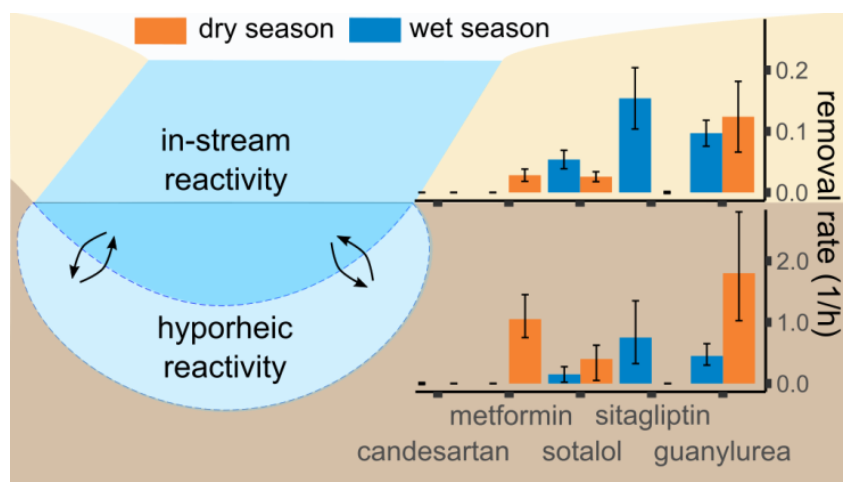

19 


\section{Abstract}

21 First-order half-lives for 26 trace organic compounds (TrOCs) were determined in the hyporheic zone 22 (HZ) and along a $3 \mathrm{~km}$ reach of a first-order stream in South Australia during both, dry and wet seasons.

23 Two salt tracer experiments were conducted and evaluated using a transient storage model to characterize 24 seasonal differences in stream residence time and transient storage. Lagrangian and time-integrated 25 surface water sampling were conducted to calculate half-lives in the surface water. Half-lives in the HZ

26 were calculated using porewater samples obtained from a modified mini-point sampler and hyporheic

27 residence times measured via active heat-pulse sensing. Half of the investigated TrOCs (e.g. oxazepam,

28 olmesartan, candesartan) were not significantly removed along both the investigated river stretch and the

29 sampled hyporheic flow paths. The remaining TrOCs (e.g. metformin, guanylurea, valsartan) were found

30 to be significantly removed in the $\mathrm{HZ}$ and along the river stretch with relative removals in the $\mathrm{HZ}$

31 correlating to reach-scale relative removals. Using the modeled transport parameters, it was estimated that

32 wet season reach-scale removal of TrOCs was predominately caused by removal in the HZ when the

33 intensity of hyporheic exchange was also higher. Factors that increase HZ exchange are thus likely to 34 promote in-stream reactivity of TrOCs.

\section{Keywords}

36 Pharmaceuticals, urban water cycle, transient storage, hyporheic zone, metformin 


\section{Introduction}

38 Trace organic compounds (TrOCs) originating from wastewater treatment plants (WWTPs) are frequently

39 detected in urban rivers, ${ }^{1,2}$ in which they have adverse effects on aquatic ecosystems ${ }^{3-6}$ and pose risks for

40 drinking water production. ${ }^{7}$ The in-stream removal of TrOCs in rivers is driven by a variety of physio-

41 chemical and biological processes. Some of these removal processes (photolysis and volatilization) are

42 restricted to surface water. Others such as sorption and abiotic and microbially mediated transformation

43 and degradation processes occur predominately at the water-sediment interface, in biofilms growing on

44 stones and macrophytes and river sediments. ${ }^{8-10}$ The hyporheic zone (HZ) is defined as the portion of river

45 sediments that acts as an interface and mixing zone between groundwater and surface water. Hyporheic

46 sediments are typically characterized by steep redox gradients, increased reactive surface areas, high

47 microbial turnover rates and diverse microbial communities and are therefore considered to act as efficient

48 bioreactors. ${ }^{11-13}$ Compared to other saturated subsurface environments, reactivity of TrOCs in the HZ is

49 relatively high, primarily due to higher chemical turnover rates in the HZ. ${ }^{14}$ Both laboratory ${ }^{15,16}$ and field

50 studies ${ }^{14,17}$ further demonstrated that the HZ is capable of removing TrOCs, even along short (cm) flow

51 paths. A number of studies have consequently attributed a large proportion of the observed in-stream

52 removal at the reach-scale to removal processes in the HZ. ${ }^{18-20}$

53 The relative contribution of the $\mathrm{HZ}$ to in-stream removal of TrOCs, and thus the significance of hyporheic

54 zones, is not only a function of the reactivity of TrOCs in the $\mathrm{HZ}$ but is also controlled by physical

55 exchange flows between the $\mathrm{HZ}$ and the surface water. In previous studies on the in-stream fate of TrOCs,

56 exchange flows between the $\mathrm{HZ}$ and the surface water were either not quantified ${ }^{19,20}$ or found to be

57 relatively small. ${ }^{9,18}$ Therefore, the relative importance of removal processes in the HZ for reach-scale in-

58 stream removal of TrOCs as a function of the intensity of hyporheic exchange fluxes remains poorly

59 understood. While the fate of some TrOCs such as neuro-active pharmaceuticals, ${ }^{18}$ endocrine disruptors ${ }^{9}$

60 and beta blockers, ${ }^{19}$ in rivers has been investigated previously, quantitative information on the reactivity of 
61 many other TrOCs, such as the antidiabetic drugs metformin and sitagliptin and compounds of the sartan 62 group, and their transformation products in lotic systems is widely lacking.

63 The aims of the present study were (i) quantify both the in-stream and hyporheic reactivity (i.e. half-lives) 64 of several TrOCs and their respective transformation products in a WWTP effluent dominated stream, and 65 (ii) quantify the relative contribution of hyporheic removal to in-stream (i.e. reach-scale) removal of 66 TrOCs. To this end, we determined stream transport characteristics and both the in-stream and the HZ 67 reactivity of 26 TrOCs including 19 parent compounds and 7 transformation products during wet and dry 68 seasons in a first-order stream in South Australia. We hypothesize that in a small, first-order stream the 69 fate of many TrOCs will be largely controlled by their respective reactivity in the HZ as well as the 70 intensity of hyporheic exchange fluxes. 


\subsection{Site description and salt tracer experiments}

74 The present study was conducted in a $3 \mathrm{~km}$ section of the Sturt River; a first-order stream in South 75 Australia located in the Adelaide Hills (Figure SI-01). The Sturt River originates at the outlet of a small, 76 municipal wastewater treatment plant (WWTP Heathfield). Consequently, at its source (Site A) the Sturt 77 River contains close to $100 \%$ WWTP effluent. Several small ephemeral streams contribute water to the 78 Sturt River during the wet season (May to September) but not during the dry season (October to April).

79 Due to the Mediterranean climate in South Australia, surface water and porewater temperatures in the 80 Sturt River are, on average, $5{ }^{\circ} \mathrm{C}$ higher during the dry than the wet season (Figure SI-02). Mean $( \pm 1$ 81 standard deviation, SD) river sediment porosity $(\theta)$ determined from 40 oven dried $\left(105^{\circ} \mathrm{C}, 48 \mathrm{~h}\right)$ sediment 82 samples taken using KSAT rings (Meter, Germany) at various locations between Site A and B was $0.4 \pm$ 83 0.06. Saturated hydraulic conductivities $(\mathrm{K})$ at $10^{\circ} \mathrm{C}$, measured in the same samples using a KSAT device 84 (Meter, Germany), were found to be log-normally distributed with a mean of $1.7 \times 10^{-4} \mathrm{~m} \mathrm{~s}^{-1}$ and a SD of $851.2 \times 10^{-3} \mathrm{~m} \mathrm{~s}^{-1}$. Mean $(1 \pm \mathrm{SD})$ sediment organic matter content $\left(\mathrm{f}_{\mathrm{oc}}\right)$ determined in a subset of 6 samples 86 by loss on ignition was $0.9 \pm 0.2 \mathrm{wt} \%$. Mean surface water $\mathrm{pH}$, measured at Site A using a YSI 87 multiparameter probe (ProDSS YSI, USA) was $7.2 \pm 0.1$ during the wet and $7.5 \pm 0.1$ during the dry season experiments.

89 Two salt tracer experiments were conducted on October $7^{\text {th }} 2016$ and March $16^{\text {th }} 2017$ (corresponding to

90 wet and dry seasons, respectively) to estimate hydrological transport characteristics, such as the magnitude

91 of transient storage and hydraulic residence times. During both experiments, a salt tracer solution $\left(75 \mathrm{gL}^{-1}\right.$

$92 \mathrm{NaCl}$ ) was injected into the surface water at the WWTP outlet (Site A, Figure SI-01) over a $1 \mathrm{~h}$ period at a 93 constant rate using a submersible pump (MP1, Grundfos, Denmark). Breakthrough curves of electrical 94 conductivity (EC) were measured in the surface water at two locations downstream (Site A - after mixing 95 length $0.1 \mathrm{~km}$ downstream of the WWTP outlet; Site B - $3 \mathrm{~km}$ downstream of Site A) using CTD Loggers 
96 (Aqua TROLL 200, In-Situ, USA). Streamflow during the tracer experiment at Site A was provided by SA

97 Water (owner and operator of the Heathfield WWTP). 


\subsection{Water Sampling}

99 During the wet season (September 2016) experiment, time-integrated, hourly surface water samples were

100 collected at Sites A and B over the course of $24 \mathrm{~h}$ from 00:00 on September $26^{\text {th }}$ to 00:00 on September $27^{\text {th }}$ 2016. All surface water samples were taken using an automatic water sampler (model 3700 , Teflon

102 suction line, Teledyne ISCO, Lincoln, NE.). During the March 2017 experiment, 6 and 8 surface water 103 grab samples were collected during tracer breakthrough at Sites A and B, respectively. Samples of 104 hyporheic porewater were collected using self-constructed minipoint samplers. ${ }^{21,22}$ Mini-points consisted 105 of HPLC tubes (PEEK, ID 0.03 inch, Sigma Aldrich, USA) inserted into $1.5 \mathrm{~m}$ long stainless steel tubes 106 (ID $0.7 \mathrm{~mm}$ ) with laser-cut, 1-cm long screens at the sealed tips. The HPLC tube was connected to 6107 channel syringe pumps (NE-1600 New Era Pump Systems, Inc, Farmingdale, USA) via Swagelok fittings 108 (Swagelok, USA). Ten $\mathrm{ml}$ of hyporheic porewater was sampled at a constant sampling rate of $1 \mathrm{ml} \mathrm{min}^{-1}$.

109 Porewater samples were taken along the upper section of the investigated river reach (Figure SI-01) at two 110 depths in the HZ; 10 and $15 \mathrm{~cm}$. During the wet season sampling event, 7 and 5 porewater samples were 111 taken over the course of $3 \mathrm{~h}$ from the two depths respectively. Compared to the dry season event where 7 112 and 4 samples were taken over the course of $4.5 \mathrm{~h}$ at the two depths. At every sampling site, porewater 113 velocities were measured via active heat pulse sensing. ${ }^{23}$ The instrument injected one-minute heat pulses 114 in the HZ and used the resulting measured temperature breakthrough curves to estimate Darcy flow 115 velocities and thermal properties of the sediment in approximately 7.5 and $15 \mathrm{~cm}$ depth. Estimated Darcy 116 flows were subsequently divided by sediment porosity to estimate porewater velocities. During the wet 117 season porewater samples were taken on September $26^{\text {th }}$ and were thus related to surface water samples 118 taken on the same day. During the dry season porewater samples were taken on March $20^{\text {th }}$ and related to 119 surface water grab samples taken hourly over the course of $16 \mathrm{~h}$ prior to porewater sampling on the same 120 day. Differences in sampling methodology between the two experiments resulted from the fact that due to 121 field site logistical issues during the wet season, the stream tracer test was conducted 10 days after water 122 sampling took place. Transferability of the transport characteristics was assumed because hydrological 
123 conditions on September $27^{\text {th }}$ and October $7^{\text {th }}$ were relatively similar (inferred from stream stage data),

124 particularly when compared to differences in streamflow between the two seasons (see SI for detailed 125 discussion).

126 All samples were filtered on site using regenerated cellulose filters ( $0.2 \mu \mathrm{m}$, Macherey-Nagel, Germany) 127 for TrOCs and cellulose acetate syringe filters $(0.2 \mu \mathrm{m}$, Sartorius, Germany) for anion and cation analysis 128 (compare section 2.3). Samples for chloride and cation analysis were stored in polyethylene bottles at $4^{\circ} \mathrm{C}$ 129 until analysis. Samples for major cation and trace element analyses were acidified with nitric acid (1\% v/v $130 \mathrm{HNO}_{3}$ ). Samples for TrOCs were stored in amber glass bottles with Teflon lined caps and were frozen 131 immediately after recovery from the field.

\subsection{Analytics}

134 Samples for TrOC analysis were split and analyzed in parallel via high performance liquid 135 chromatography with tandem mass spectrometry (HPLC-MS/MS) at Technical University of Berlin 136 (TUB) following standard protocols, ${ }^{24,25}$ and at the Department of Environmental Science and Analytical 137 Chemistry (ACES) at Stockholm University using a method established previously. ${ }^{22}$ Separation was 138 achieved using a XSelect HSS T3 HPLC column $(2.5 \mu \mathrm{m}$ particle size, $2.1 * 50 \mathrm{~mm}$, Waters, USA) at

139 TUB and an Acquity UPLC HSS T3 column $(1.8 \mu \mathrm{m}, 2.1 \mathrm{~mm} \times 100 \mathrm{~mm}$, Waters, USA) at ACES using

140 linear gradients (ultra-pure water versus 100\% methanol; HPLC grade, J.T. Baker, USA). A TSQ Vantage 141 and a Quantiva triple-quadrupole mass spectrometer (Thermo Fisher Scientific, USA) in ESI \pm modes 142 were used for MS/MS analysis at TUB and ACES, respectively. We analyzed 54 TrOCs, including 34 143 parent compounds (PCs) and 20 transformation products (TPs). In both methods, compound identification 144 was achieved using the characteristic ratio of two ion fragments. Quantification was achieved using 145 isotope-substituted standards (Toronto Research Chemicals, Canada) in combination with the most 146 abundant fragment ion (Table SI-01). Calibration standards were measured before and after the sampling 147 sequences in both methods. Details on linear gradients, respective internal standards, limits of detection 
148 (LODs) and quantification (LOQs) for each target compound and a detailed description of the TUB 149 method are provided in the SI. A detailed description of the ACES quantification method can be found in 150 Posselt et al. 2018 (in press). Chloride concentrations in tracer test samples were determined by ion151 chromatography (Metrohm, Switzerland, DIN EN ISO 10304-1 \& Dionex ICS-2500, Thermo Fisher, 152 USA). Cations and trace metals were analyzed by a Perkin Elmer NexION 350D Inductively Coupled 153 Plasma Mass Spectrometer at Flinders University, Adelaide, South Australia. All ion balances were better 154 than $\pm 5 \%$. 


\subsection{Relative removal and first-order removal rate constants}

156 The relative removal $(\%)$ and first-order removal rate constants in the river between Site A and B and

157 between the surface water and the hyporheic porewater were calculated by normalizing TrOC

158 concentrations to those of a stable reference compound. ${ }^{19,20}$ This method requires (i) relatively stable

159 hydrological conditions during the sampling period, (ii) relatively constant compound ratios in the WWTP

160 effluent, and (iii) the absence of other sources of TrOCs in the investigated stream reach. All of these

161 assumptions were met in the present study as river discharge fluctuations at Site B during sampling were

162 relatively small (Figures SI-03 \& 04) and concentrations of TrOCs in the WWTP effluent were found to

163 be close to time invariant over the sampling events (Table SI-06). Additional, diffuse inputs of TrOCs

164 from other sources such as septic tanks can be assumed to be negligible because acesulfame (ACS), often

165 associated with this source, ${ }^{26}$ behaved conservatively in the surface water and concentrations of ACS did

166 not increase relative to stable reference compounds during both sampling events. We used carbamazepine

167 (CBZ) as a stable reference compound as it has previously been shown to behave highly persistent in lotic

168 systems and saturated sediments ${ }^{14,19,27}$ and was used as a stable reference compound previously. ${ }^{20}$

169 Candesartan (CAN), a compound that can also be considered to behave rather persistent in saturated

170 sediments ${ }^{27}$ and in streams (present study), was used to cross-validate the approach (Figure SI-10).

171 For each sampling event, the relative removal for each $\operatorname{TrOC}\left(\operatorname{Rel}_{\mathrm{x}}\right)$ was calculated via:

$$
\operatorname{Rel}_{x}=\left(1-\frac{C_{r e f, \text { SiteA }}}{C_{\text {ref,SiteB }}} \frac{C_{x, \text { SiteB }}}{C_{x, \text { SiteA }}}\right) \times 100 \%
$$

172 in which $\mathrm{C}_{\text {ref,SiteA }}$ and $\mathrm{C}_{\text {ref,SiteB }}$ are the mean concentrations of the reference compound CBZ at Site A and

173 Site B and $\mathrm{C}_{\mathrm{x}, \mathrm{SiteA}}$ and $\mathrm{C}_{\mathrm{x}, \mathrm{SiteB}}$ are the mean concentrations of a TrOC at Site A and Site B, respectively. For 174 calculation purposes, concentrations of TrOCs larger than their LOD, but smaller than their LOQ, were set 175 to their respective LOQ. Removal of TrOCs was considered significant if the $95 \%$ percentile of the 
176 relative removal did not include zero. For TrOCs that were significantly removed, first-order in-stream

177 removal rate constants $(\mathrm{k})$ were calculated for from log-transformed normalized concentration ratios:

$$
k=-\ln \left(\frac{C_{r e f, \text { Site } A}}{C_{\text {ref,SiteB }}} \frac{C_{x, \text { SiteB }}}{C_{x, \text { Site } A}}\right) t_{\text {med }}^{-1}
$$

178 whereby $t_{m e d}$ denotes the median travel time $(\mathrm{h})$ between Sites A and B. Compound half-lives $\left(\mathrm{t}_{1 / 2}\right)$ were 179 calculated from first-order removal rate constants via:

$$
t_{1 / 2}=\frac{\ln (2)}{k}
$$

180 For TrOCs that were not significantly removed, first-order removal rate constants were set to zero and 181 compound half-lives to infinity. Relative removal in the $\mathrm{HZ}$ was calculated using equation 1, whereby Site 182 B denotes the porewater sample in the $\mathrm{HZ}$ and Site $\mathrm{A}$ is the mean surface water concentration. First-order 183 removal rate constants in the $\mathrm{HZ}$ were calculated using equation 2 , in which $\mathrm{t}_{\mathrm{med}}$ was replaced with the 184 residence time in the $\mathrm{HZ}$ at the respective sampling depth $\left(\mathrm{t}_{\mathrm{hz}}\right)$. Hyporheic residence times were calculated 185 from measured porewater velocities using the respective sampling depths. 


\subsection{River transport characteristics}

187 River transport characteristics were derived from the measured salt-tracer breakthrough curves using an 188 extended version of the one-dimensional advection-dispersion transient storage model (TSM), ${ }^{28}$ which is 189 discussed in detail in the SI. In brief, the original transient storage equations were transformed into a 190 system of ordinary differential equations (ODEs) by eliminating the time derivate using the Laplace 191 Transform Galerkin Technique. ${ }^{29}$ The resulting set of ODEs was then solved numerically using a finite 192 element discretization before it was back transformed to real space using the DeHoog algorithm. ${ }^{30}$ An 193 evolutionary Monte Carlo Markov chain embedded in the DREAM algorithm ${ }^{31}$ was used to minimize the 194 model likelihoods and produce parameter probability density distributions for streamflow at Site A $\left(Q_{\text {site }}\right.$ $195 \mathrm{~A})$, cross-sectional area of the main channel $\left(\mathrm{A}_{\mathrm{sw}}\right)$, and the transient storage zone $\left(\mathrm{A}_{\mathrm{s}}\right)$, first-order transient 196 storage coefficient $(\alpha)$, dispersion $(D)$ and lateral inflow $\left(\mathrm{Q}_{\mathrm{L}}\right.$, posterior distributions shown in Figures SI19708 \& 09). Measured EC time series were converted into time series of chloride concentration using an EC198 chloride correlation curve, which was obtained from serial dilutions using WWTP effluent and $\mathrm{NaCl}$ 199 solution from the tracer experiment. Median travel time $\left(\mathrm{t}_{\mathrm{med}}\right)$ between Site A and B was defined as the 200 time for $50 \%$ of the chloride mass to pass Site B. ${ }^{32}$ The overall magnitude of transient storage in the reach 201 can further be estimated by the fraction of median travel time due to transient storage $\left(\mathrm{F}_{\mathrm{med}}\right):^{32}$

$$
F_{\text {med }} \cong\left(1-e^{-L_{c}\left(\frac{\alpha}{u}\right)}\right)\left(\frac{A_{s}}{A_{s w}+A_{s}}\right)
$$

202 in which $A_{s w}$ and $A_{s}$ denote the cross-sectional area $\left(\mathrm{m}^{2}\right)$ of the main channel and the transient storage 203 zone, respectively, $\alpha$ the storage zone exchange coefficient $\left(\mathrm{s}^{-1}\right), \mathrm{L}_{\mathrm{c}}$ the reach length $(\mathrm{m})$ and $\mathrm{u}\left(\mathrm{m} \mathrm{s}^{-1}\right)$ the 204 surface water flow velocity. 


\subsection{Relative contribution of the $\mathrm{HZ}$ to in-stream removal of TrOCs}

206 The relative contribution of the HZ to in-stream removal of TrOCs can qualitatively be assessed by 207 comparing removal percentages in the $\mathrm{HZ}$ to in-stream removal in the surface water relative to a 208 theoretical mixing line. The slope of the mixing line can be approximated by the ratio between $\mathrm{L}_{c}$, the 209 length of the river reach (distance between Site A and B) and $\mathrm{L}_{\mathrm{s}}$, the theoretical reach length water parcels 210 travel downstream before they are exchanged with the storage zone. ${ }^{32}$ Following previous formulations, ${ }^{33}$

211 and assuming that transient storage is mainly driven by streambed exchange, $\mathrm{L}_{\mathrm{s}}$ can be estimated from 212 transient storage parameters via:

$$
L_{s}=\frac{u}{\theta \alpha}
$$

213 where $u$ is the average reach-scale flow velocity calculated as $\mathrm{Q} / \mathrm{A}_{\mathrm{sw}}$. After $\mathrm{L}_{\mathrm{s}}$ meters, the entire discharge

214 will have spent a mean residence time $\tau_{\mathrm{hz}}\left(\mathrm{A}_{\mathrm{s}} / \alpha \mathrm{A}_{\mathrm{sw}}\right)$ in the transient storage zone. Using the mean 215 residence time of the sampled porewater in the $\mathrm{HZ}\left(\mathrm{t}_{\mathrm{hz}}\right), \mathrm{L}_{\mathrm{c}} / \mathrm{L}_{\mathrm{s}}$ can be corrected for not sampling porewater 216 with a mean age of $\tau_{\mathrm{hz}}$ :

$$
\frac{L_{c}}{L_{s}}=\frac{t_{h z}}{\tau_{h z}} \frac{L_{c} \theta \alpha}{u}
$$

217 See SI for derivation of equations 5 and 6 and a detailed discussion of underlying assumptions. 


\section{Results \& Discussion}

\subsection{Stream transport characteristics and hyporheic residence times}

220 Streamflow (Q), $\mathrm{A}_{\mathrm{sw}}, \mathrm{A}_{\mathrm{s}}, \alpha, \mathrm{D}$ and surface water flow velocity (Q/A) were considerably higher during the

221 wet season (Table 1). Consequently, median travel time $\left(\mathrm{t}_{\mathrm{med}}\right)$ between Sites A and B was more than twice 222 as large during the dry season experiment compared to the wet season experiment. The calculated 223 exchange $(\alpha)$ and dispersion (D) coefficients fall well within the range of values presented in previous 224 studies on streams with similar characteristics. ${ }^{32,34}$ Due to the absence of pools and dead zones in the water 225 body, the transient storage in the investigated section of the Sturt River is mainly caused by streambed 226 exchange. Higher flow velocities during the wet season cause dispersion and exchange coefficients to 227 increase ${ }^{34}$ and the hyporheic zone to expand, ${ }^{35}$ which explains the larger cross-sectional area of the 228 transient storage zone. The fraction of the median travel time due to transient storage $\left(\mathrm{F}_{\text {med }}\right)$ in the wet 229 season (0.50) was more than double that of the dry season (0.20), indicating a higher intensity of 230 hyporheic exchange during the wet season experiment. Fractions of WWTP effluent in the river system at 231 Site B, calculated using carbamazepine as a stable reference compound, were $93 \pm 2 \%$ in the dry season 232 and $57 \pm 2 \%$ in the wet season. The fraction of surface water in the $\mathrm{HZ}$ ranged from 80 to $100 \%$ during the 233 wet season and from 85 to $100 \%$ during the dry season, indicating that the contribution of groundwater to 234 hyporheic porewater was relatively small.

235 Hyporheic porewater velocities, calculated using active heat pulse sensing, ranged from 1.0 to $7.3 \mathrm{~m} \mathrm{~d}^{-1}$ 236 with median values of $2.0 \mathrm{~m} \mathrm{~d}^{-1}(\mathrm{n}=11)$ and $3.4 \mathrm{~m} \mathrm{~d}^{-1}(\mathrm{n}=12)$ during the wet and dry season, respectively 237 (Table SI-01). Assuming a log-normal distribution of the measured hyporheic residence times, mean $( \pm 1$ 238 standard deviation) hyporheic residence times $\left(\mathrm{t}_{\mathrm{hz}}\right)$ at the sampling depths were $2.0 \mathrm{~h}( \pm 1.3 \mathrm{~h})$ during the 239 wet season, compared to $1.0 \mathrm{~h}( \pm 0.6 \mathrm{~h})$ during the dry season. Measured hyporheic porewater velocities 240 compare well to values reported in previous studies. ${ }^{14,33}$ 
Table 1 Transport characteristics (streamflow at Site A $\left(\mathrm{Q}_{\mathrm{Site}} \mathrm{A}\right)$, stream cross-sectional area $\left(\mathrm{A}_{\mathrm{sw}}\right)$, cross-sectional area of the transient storage zone $\left(\mathrm{A}_{\mathrm{s}}\right)$, one-dimensional exchange coefficient $(\alpha)$ and fraction of median travel time due to transient storage $\left(\mathrm{F}_{\mathrm{med}}\right)$ ) of the investigated stream reaches modeled using the one-dimensional advection-dispersion model with transient storage. Additionally, median travel time $\left(\mathrm{t}_{\mathrm{med}}\right)$, mean surface water temperature, the proportion of WWTP effluent at Site B calculated using carbamazepine as a stable reference compound and the mean residence time in the transient storage zone $\left(\tau_{\mathrm{hz}}\right)$ as well as the mean residence time of the sampled porewater in the HZ $\left(\mathrm{t}_{\mathrm{hz}}\right)$ are shown. The length of the investigated reach was $3020 \mathrm{~m}$ in both experiments. Calculated dispersion coefficients (D) are provided in the SI.

\begin{tabular}{|c|c|c|c|c|c|}
\hline Experiment & $\begin{array}{l}\text { Q Site A } \\
\left(\mathrm{L} \mathrm{s}^{-1}\right)\end{array}$ & $\begin{array}{l}\mathrm{A}_{\mathrm{sw}} \\
\left(\mathrm{m}^{2}\right)\end{array}$ & $\begin{array}{c}\mathrm{A}_{\mathrm{s}} \\
\left(\mathrm{m}^{2}\right)\end{array}$ & $\begin{array}{c}\log _{10}(\alpha) \\
\left(\mathrm{s}^{-1}\right)\end{array}$ & $\begin{array}{l}\text { surface water } \\
\text { temperature } \\
\left({ }^{\circ} \mathrm{C}\right)\end{array}$ \\
\hline dry season & 19 & $0.25 \pm 0.01$ & $0.09 \pm 0.03$ & $-4.45 \pm 0.06$ & $19.6 \pm 2.6$ \\
\hline \multirow[t]{2}{*}{ wet season } & 52 & $0.40 \pm 0.00$ & $0.50 \pm 0.02$ & $-4.00 \pm 0.01$ & $14.9 \pm 0.3$ \\
\hline & $\mathrm{F}_{\mathrm{med}}$ & $\begin{array}{l}\mathrm{t}_{\text {med }} \\
(\mathrm{h})\end{array}$ & $\mathrm{t}_{\mathrm{hz}}$ & $\begin{array}{l}\tau_{\mathrm{hz}} \\
\text { (h) }\end{array}$ & $\begin{array}{c}\text { WWTP effluent, } \\
\text { Site B } \\
(\%)\end{array}$ \\
\hline dry season & $0.20 \pm 0.01$ & 12.2 & $1.0 \pm 0.6$ & $2.8 \pm 1.1$ & $93 \pm 2$ \\
\hline wet season & $0.50 \pm 0.01$ & 4.9 & $2.0 \pm 1.9$ & $3.4 \pm 0.2$ & $57 \pm 2$ \\
\hline
\end{tabular}




\subsection{Occurrence of TrOCs in WWTP effluent}

251 Twenty-five TrOCs, including 19 PCs and 6 TPs were consistently detected above their respective LOQ at 252 the WWTP outlet (Site A) during both the wet and dry season sampling events (Figure 1). 4253 Hydroxydiclofenac (HDF), a TP of diclofenac (DCF) was only detected during the wet season. During the 254 wet season, median TrOC concentrations ranged from $0.04 \mu \mathrm{g} / \mathrm{L}$ for epoxy-carbamazepine (EBZ) to 48.3 $255 \mu \mathrm{g} / \mathrm{L}$ for guanylurea (GUA, Table SI-06). TrOCs concentrations in the WWTP effluent during the dry 256 season experiment ranged from $0.04 \mu \mathrm{g} / \mathrm{L} \mathrm{EBZ}$ to $15.1 \mu \mathrm{g} / \mathrm{L}$ olmesartan (OLM). For the majority of 257 TrOCs, concentrations at Site A were relatively constant during both porewater and surface water 258 sampling. Relative standard deviations of mean surface water concentrations ranged from 3\% for OLM 259 and benzotriazole (BTA) to $21 \%$ for EBZ, from $2 \%$ for GPL to $68 \%$ for HDF and from $2 \%$ for VSA to $26056 \%$ for HDF, during the wet season, dry season tracer and dry season porewater sampling events (Table 261 SI-06).

262 The concentrations of 14 compounds were significantly higher during the dry season experiments than in 263 the wet season experiments (Kruskal-Wallis tests, p-value $<0.01$, Figure 1). For 7 compounds, 264 concentrations were significantly higher during the wet season experiment, while for 5 compounds no 265 significant differences were found. Seasonal differences in TrOC concentrations in WWTP effluents have 266 been described earlier ${ }^{18,36}$ and are commonly attributed to changes in consumption patterns, differing 267 proportions of stormwater and wastewater entering the WWTP as well as temperature driven changes in 268 WWTP removal efficiency. For instance, ratios of valsartan (VAL) to its main TP valsartan acid (VSA, 269 compare section 3.3) were significantly higher during the wet season sampling event (Figure SI-11), 270 indicating that with higher temperatures transformation efficiency of VAL in the WWTP increases and 271 thus PC:TP ratios (parent compound to transformation product) decrease. On the contrary, PC:TP ratios 272 for CBZ to two of its TPs EBZ and DBZ and for venlafaxine (VLX) to its main TP $O$-desmethyl273 venlafaxine (MLX) remained relatively constant during both sampling events, although concentrations of 274 these compounds were higher in the dry season. As large changes in consumption patterns for these 


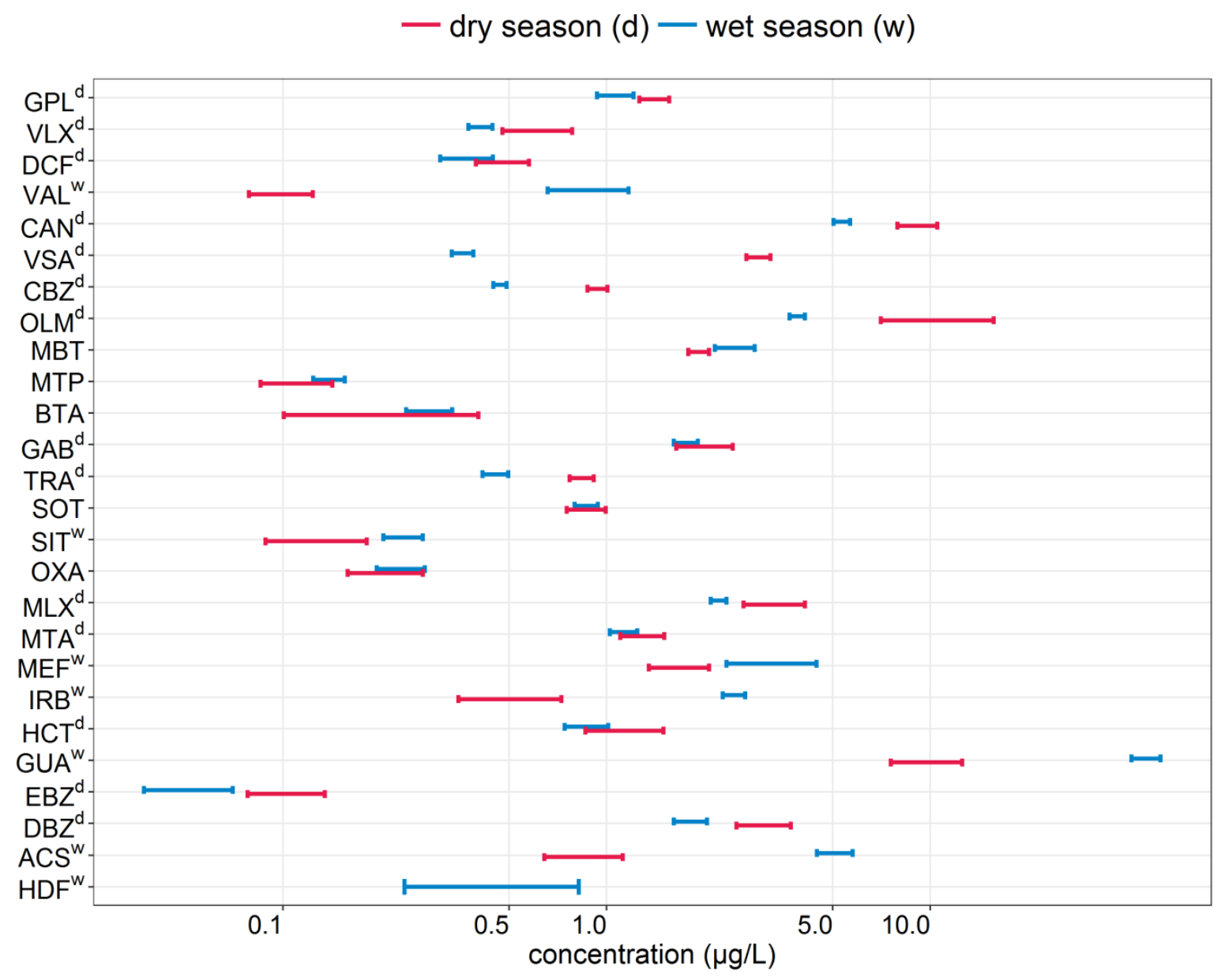

Figure 1 Concentration ranges for the 25 TrOCs that were detected consistently above their respective limit of quantification (LOQ) during the wet and the dry season sampling events at Site A. The concentration range of 4-hydroxydiclofenac (HDF), which was only detected above its LOQ during the wet season is depicted as well. Superscripts indicate whether concentrations were significantly higher (Kruskal-Wallis tests, $\mathrm{p}$ value <.01) during the dry season sampling events (d) or wet season sampling events (w). GPL, gabapentin-lactam; VLX, venlafaxine; DCF, diclofenac; VAL, valsartan; CAN, candesartan; VSA, valsartan acid; CBZ carbamazepine; OLM olmesartan; MBT, methylbenzotriazole; MTP, metoprolol; BTA, benzotriazole; GAB, gabapentin; TRA, tramadol; SOT, sotalol; SIT, sitagliptin; OXA, oxazepam; MLX, $O$-desmethylvenlafaxine; MTA, metoprolol acid; MEF, metformin; IRB, irbesartan; HCT, hydrochlorothiazide; GUA, guanylurea; EBZ, epoxy-carbamazepine; DBZ, dihydroxy-carbamazepine; ACS, acesulfame. 


\subsection{In-stream reactivity of TrOCs}

288 Relative removal (half-lives) in the surface water between Site A and B ranged from $21 \pm 5 \%(14.0 \pm 3.9$

$289 \mathrm{~h}$ ) for methylbenzotriazole (MBT) to $53 \pm 12 \%(4.5 \pm 1.5 \mathrm{~h})$ for sitagliptin (SIT) during the wet season 290 and from $20 \pm 8 \%(38.9 \pm 18.2 \mathrm{~h})$ for VLX to $78 \pm 16 \%(5.6 \pm 2.6 \mathrm{~d})$ for GUA during the dry season, 291 respectively (Table 2, Figure 2, Table SI-05). All TrOCs that were detected above their respective LOQ at 292 Site A, were still present above their LOQ at Site B.

293 The beta blockers, metoprolol (MTP) and sotalol (SOT) as well as diclofenac (DCF) were found to be 294 readily removed in streams in Germany and Sweden (discharge $0.03-6 \mathrm{~m}^{3} \mathrm{~s}^{-1}$ ) ${ }^{19,20}$ which is in qualitative 295 agreement with the findings in the present study. Li et al. ${ }^{19}$ attributed higher removal of SOT and MTP to 296 higher hyporheic exchange fluxes, although the magnitude of transient storage was not assessed in their 297 study. Valsartan, an angiotensin II receptor antagonist, was the only compound of the sartan group that 298 was significantly removed along the investigated river stretch. This finding is in agreement with previous 299 studies that reported that the compound is readily transformed to valsartan acid (VSA) in aquatic 300 environments. ${ }^{37}$ The half-lives of VAL calculated in the present study $(11.2-12.5 \mathrm{~h})$ are an order of 301 magnitude higher than the mean half-life reported in a study conducted along four river stretches in Spain

$302\left(\mathrm{t}_{\mathrm{med}} 2.2 \mathrm{~h}\right.$, discharge $\left.0.05-2.7 \mathrm{~m}^{3} \mathrm{~s}^{-1}\right) .{ }^{38}$ During the wet season sampling event, concentrations of VSA 303 increased between Site A and B, while during the dry season sampling event concentrations remained 304 relatively constant. Similar to observations in the HZ (compare section 3.4), this finding is likely due to a 305 seasonal shift in PC:TP ratios in the WWTP effluent. During the dry season, VAL was already largely 306 transformed to VSA during wastewater treatment, while during the wet season a larger proportion of VAL 307 leaves the WWTP unchanged, allowing measurable transformation of VAL to VSA along the investigated 308 river reach. Once transformed, VSA was found to be stable in both sampling events, which is supported 309 by studies that reported the widespread occurrence of the compound in urban surface waters and tap 310 water. ${ }^{37}$ The antidepressant venlafaxine and its TP $O$-desmethylvenlafaxine were found to be rather stable 311 along a $5 \mathrm{~km}$ reach of Boulder Creek, Colorado, ${ }^{18}$ while both compounds were significantly removed 
312 along the $3 \mathrm{~km}$ reach investigated in the present study. However, the magnitude of hyporheic exchange 313 reported for Boulder Creek was an order of magnitude smaller $\left(\mathrm{F}_{\mathrm{med}} \approx 0.03\right)$ than in the Sturt River 314 (section 3.1). Quantitative information on the in-stream removal of the anti-corrosive agent 5-methyl-1H315 benzotriazole (MBT), the anti-diabetic drugs sitagliptin (SIT) and metformin (MEF) as well as its main TP 316 guanylurea $(\mathrm{GUA})^{39}$ in streams is limited and thus a direct comparison of the calculated half-lives is 317 difficult. MEF and GUA have both been detected ubiquitously in surface waters ${ }^{40}$ and even in sea water, ${ }^{41}$ 318 which raised concerns on their environmental persistence. Previous studies reported that once formed, 319 GUA behaved rather stable in aquatic environments and sediments. ${ }^{39}$ Based on the results of the present 320 study, this finding cannot be confirmed as GUA was significantly attenuated in both surface water and 321 hyporheic porewater.

322 Thirteen out of the 26 TrOCs that were consistently detected above LOQ at Site A were not significantly 323 removed along the investigated river stretch in both sampling campaigns (Table SI-07). Relatively low 324 relative removals (\%) as found in the present study have also been reported for the opioid analgesic 325 tramadol (TRA) and the diuretic hydrochlorothiazide (HCT) in the study of Li et al. (2015). ${ }^{42}$ The anti326 epileptic drug carbamazepine and two of its TPs, epoxy-carbamazepine and dihydroxy-carbamazepine as 327 well as the artificial sweetener acesulfame (ACS), were found to be stable in a German and three Swedish 328 rivers, ${ }^{19}$ which is in accordance with the data reported in the present study. Quantitative data on the fate of 329 the three other sartans investigated in the present study, (i.e. irbesartan, olmesartan and candesartan), the 330 anti-corrosive agent benzotriazole (BTA), the antianxiety agent oxazepam (OXA) and the anticonvulsant 331 gabapentin (GAB) and its main TP, gabapentin-lactam (GPL) in lotic environments is limited. OXA was 332 found to be persistent over several decades in a Swedish lake. ${ }^{43}$ Given the comparatively short median 333 travel time in the investigated river reach we did not expect significant removal of this compound. The 334 frequent detection of the BTA in urban surface waters ${ }^{44}$ and the occurrence of the anticonvulsant GAB and 335 its TP GPL in drinking water ${ }^{45}$ indicate that these compounds are rather stable in surface waters. 
336 The only TP that increased along the investigated river stretch was VSA during the wet season. For all 337 investigated PCs (excluding VAL), transformation to TPs seems to be limited to the WWTP. This finding 338 is in agreement with previous observations demonstrating that the majority of PC:TP ratios stayed 339 relatively constant in receiving waters. ${ }^{19}$

340 For MLX, SIT, SOT, MBT, MTP, VSA, MEF and DCF, half-lives and thus in-stream reactivity differed 341 between the two sampling events, while for GUA, VAL and VLX similar half-lives were calculated for 342 both dry and wet seasons. For half of the TrOCs that were significantly removed between Site A and B 343 (SIT, VLX, MLX, MTP, SOT, MBT), in-stream half-lives $\left(t_{1 / 2}\right)$ were considerably lower during the wet 344 season (Table 2) although temperatures and presumably global radiation were higher during the dry 345 season. This finding is in agreement with a larger proportion of the median travel time due to transient 346 storage $\left(\mathrm{F}_{\mathrm{med}}\right)$ during the wet season. It is therefore likely that the higher reactivity of TrOCs during the 347 wet season (i.e. lower half-lives) can be attributed to a higher intensity of hyporheic exchange. 
Table 2 Surface water half-lives ( $\mathrm{t}_{1 / 2}$, hours, \pm 1 standard deviation) and median (lower quartile- upper quartile) hyporheic halflives ( $\mathrm{t}_{1 / 2}$, hours, \pm 1 standard deviation) of all trace organic compounds that were significantly removed between Site A and B 350 either during the dry or the wet season. Half-lives were set to infinity (inf) if the 95\% percentile of their respective relative 351 removal (\%) included zero. Negative half-lives indicate compound formation. Note that for HDF, concentrations at Site A during 352 the dry season were largely between its LOD and LOQ and hence reactivity of HDF during the dry season could not be assessed.

\begin{tabular}{|c|c|c|c|c|c|}
\hline \multirow[t]{2}{*}{ TrOC } & \multirow[t]{2}{*}{ acronym } & \multicolumn{2}{|c|}{$\begin{array}{l}\text { in-stream reactivity } \\
\qquad t_{1 / 2}(h)\end{array}$} & \multicolumn{2}{|c|}{$\begin{array}{l}\text { median hyporheic reactivity } \\
\qquad t_{1 / 2}(h)\end{array}$} \\
\hline & & wet season & dry season & wet season & dry season \\
\hline metformin & MET & n.s. ${ }^{a}$ & $24.6 \pm 8.7$ & $\inf ^{\mathrm{c}}$ & $0.7(0.5-1.0)$ \\
\hline guanylurea & GUA & $7.2 \pm 1.6$ & $5.6 \pm 2.6$ & $1.6(1.0-2.1)$ & $0.4(0.2-0.7)$ \\
\hline sitagliptin & SIT & $4.5 \pm 1.5$ & n.s. & $1.1(0.5-2.3)$ & $\inf$ \\
\hline diclofenac & DCF & n.s. & $35.0 \pm 10.8$ & $\inf$ & 1.3 (0.5-inf) \\
\hline 4-hydroxydiclofenac & HDF & $6.3 \pm 3.6$ & n.q. ${ }^{b}$ & 2.0 (0.9-Inf) & n.q. \\
\hline venlafaxine & VLX & $14.0 \pm 3.8$ & $38.9 \pm 18.2$ & $1.5(0.9-2.7)$ & $\inf$ (1.9-inf) \\
\hline$O$-desmethylvenlafaxine & MLX & $13.2 \pm 4.4$ & $18.1 \pm 5.6$ & $3.4(1.6-6.5)$ & inf \\
\hline metoprolol & MTP & $12.8 \pm 5.0$ & n.s. & 3.3 (1.7-inf) & $\inf (0.1-\inf )$ \\
\hline sotalol & SOT & $12.9 \pm 3.6$ & $26.9 \pm 8.4$ & 5.7 (2.8-inf) & 2.7 (1.2-inf) \\
\hline methylbenzotriazole & MBT & $14.0 \pm 3.9$ & $30.6 \pm 8.3$ & $2.1(1.1-4.1)$ & 1.5 (0.8-inf) \\
\hline valsartan & VAL & $11.2 \pm 6.2$ & $12.5 \pm 5.2$ & 0.9 (0.5-inf) & 0.9 (0.5-inf) \\
\hline valsartan acid & VSA & $-8.5 \pm 1.8$ & n.s. & $-1.5(-1.8--0.5)$ & $\inf$ \\
\hline
\end{tabular}

${ }^{a}$ n.s. = not significantly removed; ${ }^{b}$ n.q. $=$ not quantified (below LOQ); inf $^{c}=$ infinite half-live 


\subsection{Reactivity of TrOCs in the hyporheic zone}

355 Median removal in the $\mathrm{HZ}$ ranged from $23 \%$ for sotalol to $69 \%$ for sitagliptin during the wet season and 356 from $13 \%$ for methylbenzotriazole to $87 \%$ for guanylurea during the dry season, respectively (Figure 2, 357 Table SI-08). Similarly, median half-lives in the $\mathrm{HZ}$ ranged from $0.9 \mathrm{~h}$ for VAL to $5.7 \mathrm{~h}$ for SOT during 358 the wet season and from $0.4 \mathrm{~h}$ for GUA to $2.7 \mathrm{~h}$ for SOT during the dry season (Table 2, Table SI-09). 359 CBZ, its two main transformation products EBZ and DBZ, three compounds of the sartan group OLM, 360 CAN, IRB and BTA, TRA, GAB, its main TP GPL, OXA, and the main TP of MTP, MTA showed a 361 median relative removal (\%) of zero in the $\mathrm{HZ}$ during both sampling events. Thus these compounds were 362 considered as not significantly removed along the investigated hyporheic flow paths. ACS showed a 363 median relative removal of zero in the wet season, but was slightly removed in some profiles (median 364 removal $27 \%$ during the dry season. Reactivity of the TrOCs that were significantly removed in the HZ 365 was in the order of $\mathrm{VAL}>\mathrm{SIT}>\mathrm{VLX} \approx \mathrm{GUA} \approx \mathrm{VSA}>\mathrm{HDF} \approx \mathrm{MBT}>\mathrm{MTP} \approx \mathrm{MLX}>\mathrm{SOT}$ in the wet 366 season and GUA $\approx \mathrm{MEF} \approx \mathrm{VAL}>\mathrm{DCF}>\mathrm{MBT}>\mathrm{SOT}$ in the dry season. For some TrOCs half-lives in the 367 HZ were significantly different (Kruskal-Wallis tests, $\mathrm{p}<0.05$, Table SI-9) between the two seasons. For instance, MEF and DCF were removed during the dry season but not during the wet season, while VSA was only formed during the wet but not during the dry season. SIT, MLX and GUA were removed in both seasons with MLX and SIT exhibiting lower half-lives during the wet season while GUA showed lower half-lives during the dry season.

372 Removal of TrOCs in the HZ is generally a function of the combined effect of physical factors, such as 373 residence time and temperature, and biogeochemical factors, such as microbial transformation and 374 degradation rates, sorption to sediment and biofilms and, depending on the individual TrOC, exposure to 375 favourable redox conditions. For many TrOCs reactivities in the HZ increase with temperature ${ }^{15}$ and 376 decrease when redox conditions become increasingly anoxic (i.e. drop to iron and manganese reducing 377 conditions). ${ }^{14}$ Redox conditions along the sampled hyporheic flow paths, as judged from total dissolved 378 iron and manganese concentrations (Table SI-02), were relatively similar during both sampling events and 
379 predominantly ranged between oxic and suboxic conditions (see SI for detailed discussion). Higher 380 reactivities of MEF, GUA and DCF may therefore be attributed to higher hyporheic temperatures during 381 the dry season. Similarly to findings in the surface water, differences in half-lives of VSA between the two 382 seasons may be related to PC:TP ratios in the WWTP effluent. During the wet season, concentrations of 383 VAL in WWTP effluent and PC:TP ratios of VAL:VSA were larger compared to the dry season (compare 384 section 3.2). It is therefore likely that during the wet season concentrations of VAL were too low to 385 facilitate significant (i.e. measurable) production of VSA in the HZ.

386 The reactivities of TrOCs in the $\mathrm{HZ}$ found in the present study partly differ from compound reactivities 387 reported previously in hyporheic sediments. Removal of DCF, SOT, MBT and MTP in saturated 388 sediments, has been described in laboratory ${ }^{15}$ and field experiments. ${ }^{14,20}$ MBT and DCF, for instance, 389 showed half-lives of $4.3 \mathrm{~h}$ and $3.8 \mathrm{~h}$ in the $\mathrm{HZ}$ of an urban lowland river in Germany, ${ }^{14}$ values that are in 390 the same order of magnitude as the ones calculated for the HZ of the Sturt River (Table 2). The high 391 stability of CAN, OLM and CBZ in saturated sediments has been demonstrated in column experiments ${ }^{15,46}$ 392 and a field study. ${ }^{14}$ For other compounds such as VLX, MLX or BTA, previous studies found inconsistent 393 behaviour in the HZ. Some studies reported removal of $\mathrm{VLX}^{46}$ and BTA ${ }^{14}$ while others found MLX and $394 \mathrm{VLX}^{14,18}$ as well as BTA ${ }^{15}$ to be rather stable. Likewise, ACS and GAB showed relatively low half-lives in 395 the $\mathrm{HZ}$ of an urban lowland river, ${ }^{14}$ while the compounds appear to be rather stable in hyporheic porewater 396 of the Sturt River. Such site-specific variations in TrOC reactivity in the HZ have previously been 397 described and mainly attributed to differences in microbial communities and sediment heterogeneity. ${ }^{16}$

398 Retardation of TrOCs along hyporheic flow paths due interactions between TrOCs and sediment material 399 and biofilms was not considered in the calculation of removal rate constants. Previous studies found no 400 notable retardation for neutral TrOCs which interact with streambed sediment matrices predominantly 401 through hydrophobic partitioning, ${ }^{47}$ even for compounds that are characterized by relatively high $\log \mathrm{K}_{\mathrm{ow}}$ 402 values such as $\mathrm{CBZ}\left(\log \mathrm{K}_{\mathrm{ow}} 2.8\right) .{ }^{48}$ Likewise, sorption to sediment matrices and retardation of anionic 403 TrOCs has been found to be rather small. ${ }^{48-50}$ We therefore assumed that for TrOCs that are neutral at $\mathrm{pH}$ 
values measured in the Sturt River (e.g. BTA, MBT and CBZ, pH 7.2-7.5) and compounds that are negatively charged (e.g. ACS, VAL and DCF), sorption contribution to removal and retardation is not significant. However, it has been shown that sorption can be important for cationic TrOCs such as MEF and its TP GUA, ${ }^{51} \mathrm{VLX}^{18}$ and $\mathrm{MTP}^{52}$ and thus, these compounds may have been retarded along hyporheic flow paths. Although sorption and retardation do not influence relative removals (\%), and therefore the relative contribution of the $\mathrm{HZ}$ to in-stream removal (compare section 3.5), strong retardation would lead to an underestimation of the residence time of TrOCs in the $\mathrm{HZ}$ and hence to an overestimation of the removal rate constant. Calculated half-lives of cationic TrOCs should therefore be viewed as estimates and 412 treated with caution. A list of $\log \mathrm{D}_{\mathrm{ow}}$ and $\mathrm{pKa}$ values of the investigated TrOCs can be found in Table SI41305.

\section{$414 \quad 3.5$ Relative importance of the HZ to in-stream removal of TrOCs}

415 TrOCs that were found to be rather stable in the HZ were also found to be stable in the surface water and 416 vice versa. Median relative removal (\%) of TrOCs in the $\mathrm{HZ}$ correlated well with in-stream relative 417 removal (\%) for all TrOCs that were removed in the surface water in either the wet or the dry season 418 (Figure 2). Values of $\mathrm{L}_{\mathrm{c}} / \mathrm{L}_{\mathrm{s}}$ (equation 6) were higher during the wet season $(0.5 \pm 0.3)$ compared to the dry 419 season $(0.2 \pm 0.15)$.

420 The ratio of $\mathrm{L}_{\mathrm{c}} / \mathrm{L}_{\mathrm{s}}$ defines a theoretical mixing line that approximates the relative contribution of the 421 hyporheic zone to reach-scale, in-stream removal (\%) of TrOCs. During the wet season, the majority of 422 TrOCs plot close to the theoretical mixing line, indicating that hyporheic removal was the main driver of 423 in-stream removal of TrOCs. VAL plots below the mixing line, which might be due to an overestimation 424 of either hyporheic exchange intensity or hyporheic removal percentages. During the dry season, however, 425 the majority of TrOCs plot well above the theoretical mixing line indicating that the in-stream removal is 426 higher than the removal predicted by the mixing model and the hyporheic zone removal. For instance, 427 VLX, MBT and MLX, were only poorly removed in the HZ but showed significant removal in the surface 428 water. It is therefore likely that during the dry season, other removal processes in the main channel, such 
429 as photolysis or biotransformation in interstitial biofilms and algae mats growing on stones, submerged 430 macrophytes and riparian vegetation, ${ }^{8,53}$ gained importance.

431 The calculation of the theoretical mixing line is based on a variety of assumptions and thus should be 432 viewed as an estimate. The slope $\mathrm{L}_{c} / \mathrm{L}_{\mathrm{s}}$ is calculated from TSM parameters which assumes that the $\mathrm{HZ}$ is a 433 well-mixed compartment characterized by an exponentially-shaped residence time distribution 434 (RTD). ${ }^{28}$ Although widely used, the TSM is often criticized for its inability to describe longer residence 435 times and hence its tendency to favor shorter flow paths. ${ }^{54,55}$ This is often evident by the inability of the 436 exponential RTD model to match late time breakthrough. ${ }^{56}$ However, in our study the TSM with an 437 exponential RTD was able to reproduce stream breakthrough curves well (SI section 3.2). Furthermore, it 438 is likely that removal rates of TrOCs are highest in the shallow $\mathrm{HZ},{ }^{14}$ where carbon turnover rates are 439 highest and redox conditions are oxic. ${ }^{12}$ It is therefore reasonable to assume that short flow paths 440 contributed more to overall reach-scale removal of the reactive TrOCs and hence the use of an 441 exponentially shaped RTD to calculate $\tau_{\mathrm{hz}}$ is adequate.

442 The present study demonstrates that, for many TrOCs, in-stream removal and reactivity are to a large 443 extent driven by both compound reactivity (half-lives) in the HZ and the intensity of hyporheic exchange 444 fluxes. We thus conclude that river restoration measures seeking to increase the magnitude of exchange 445 fluxes between surface water and the HZ are likely to increase the reactivity of TrOCs on the reach-scale 446 and the efficiency of rivers to remove TrOCs. However, we also found that some TrOCs were not 447 removed along the $3 \mathrm{~km}$ reach during both dry and wet seasons. These compounds may be transported 448 downstream over longer distances with potential consequences for water management, particularly in 449 urban areas where water cycles are partially closed. 


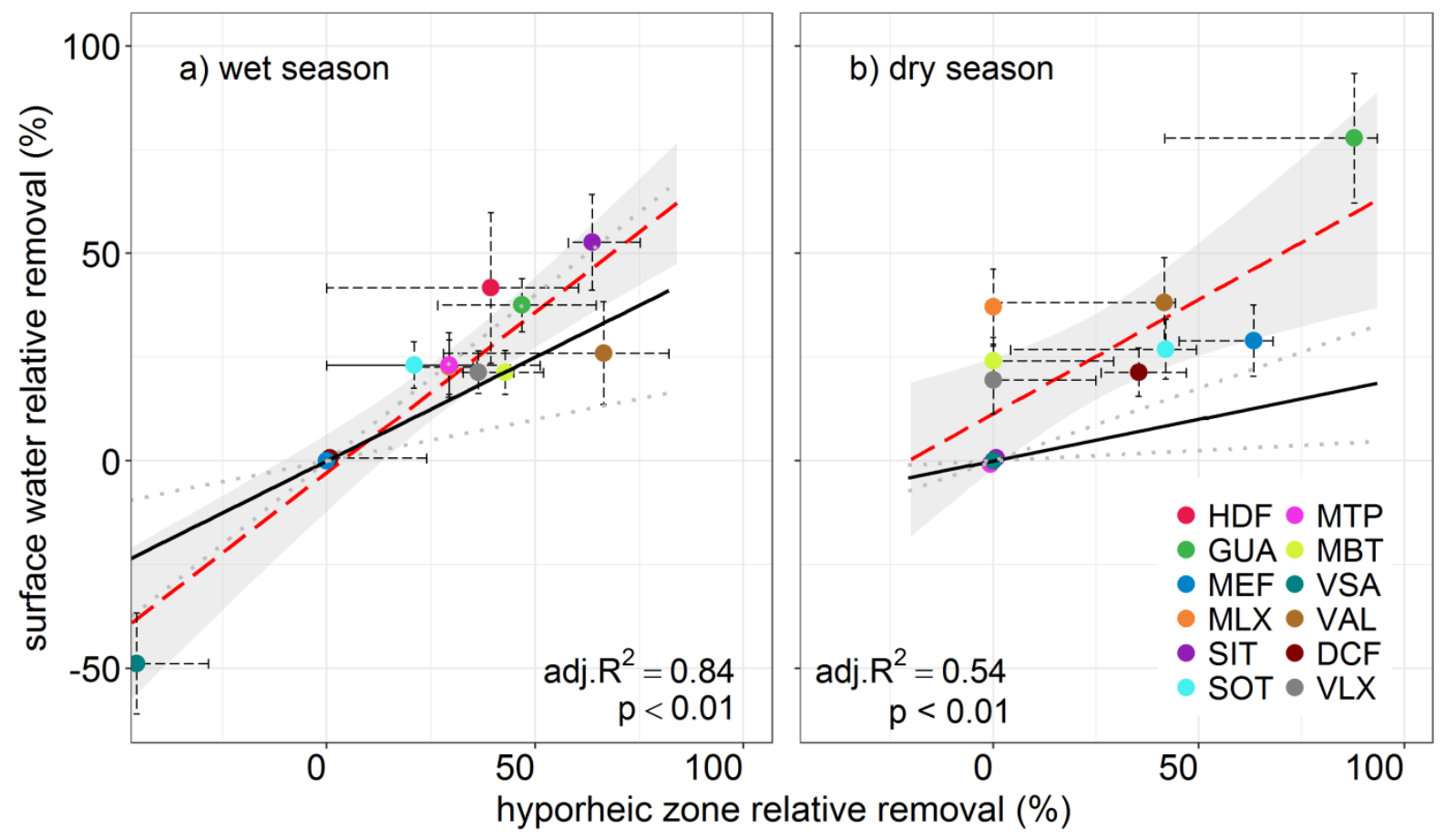

451 Figure 2 Correlation (red dashed line and associated 95\% confidence interval in grey) between the median hyporheic relative removal (\%) and the reach-scale relative removal between Site A and Site B during the wet season (a) and the dry season (b). The black line represents a theoretical mixing line with a slope of $\mathrm{L}_{\mathrm{c}} / \mathrm{L}_{\mathrm{s}}$ that depicts the predicted in-stream removal (\%) given a relative removal in the (HZ) after a mean residence time in the transient storage zone of $\tau_{\mathrm{hz}}$. Error ranges $( \pm 1$ standard deviation) of the theoretical mixing line are shown with a grey dotted line. Regression lines and associated $95 \%$ confidence intervals are plotted in red and grey shading, respectively. Note that HDF was only detected above LOQ during the wet season experiments. 


\section{References}

458 (1) Loos, R.; Carvalho, R.; António, D. C.; Comero, S.; Locoro, G.; Tavazzi, S.; Paracchini, B.;

Ghiani, M.; Lettieri, T.; Blaha, L.; et al. EU-Wide Monitoring Survey on Emerging Polar Organic Contaminants in Wastewater Treatment Plant Effluents. Water Res. 2013, 47 (17), 6475-6487.

(3) Brodin, T.; Fick, J.; Jonsson, M.; Klaminder, J. Dilute Concentrations of a Psychiatric Drug Alter

(4) Schwarzenbach, R. P.; Egli, T.; Hofstetter, T. B.; von Gunten, U.; Wehrli, B. Global Water Pollution and Human Health. Annu. Rev. Environ. Resour. 2010, 35 (1), 109-136.

(6) Niemuth, N. J.; Jordan, R.; Crago, J.; Blanksma, C.; Johnson, R.; Klaper, R. D. Metformin Exposure at Environmentally Relevant Concentrations Causes Potential Endocrine Disruption in Adult Male Fish. Environ. Toxicol. Chem. 2015, 34 (2), 291-296.

(7) Pal, A.; He, Y.; Jekel, M.; Reinhard, M.; Gin, K. Y. H. Emerging Contaminants of Public Health Significance as Water Quality Indicator Compounds in the Urban Water Cycle. Environment International. Elsevier Ltd 2014, pp 46-62.

(8) Kunkel, U.; Radke, M. Reactive Tracer Test to Evaluate the Fate of Pharmaceuticals in Rivers. Environ. Sci. Technol. 2011, 45 (15), 6296-6302.

(9) Writer, J. H.; Ryan, J. N.; Keefe, S. H.; Barber, L. B. Fate of 4-Nonylphenol and 17ß-Estradiol in the Redwood River of Minnesota. Environ. Sci. Technol. 2012, 46 (2), 860-868. 
(10) Gurr, C. J.; Reinhard, M. Harnessing Natural Attenuation of Pharmaceuticals and Hormones in Rivers. Environ. Sci. Technol. 2006, 40 (9), 2872-2876.

(11) Boano, F.; Harvey, J. W.; Marion, A.; Packman, A. I.; Revelli, R.; Ridolfi, L.; Wörman, A. Hyporheic Flow and Transport Processes: Mechanisms, Models, and Bioghemical Implications. Rev. Geophys. 2014, 52, 603-379.

(12) Knapp, J. L. A.; González-Pinzón, R.; Drummond, J. D.; Larsen, L. G.; Cirpka, O. A.; Harvey, J. W. Tracer-Based Characterization of Hyporheic Exchange and Benthic Biolayers in Streams. Water Resour. Res. 2017.

(13) Krause, S.; Lewandowski, J.; Grimm, N. B.; Hannah, D. M.; Pinay, G.; McDonald, K.; Martí, E.; Argerich, A.; Pfister, L.; Klaus, J.; et al. Ecohydrological Interfaces as Hot Spots of Ecosystem Processes. Water Resour. Res. 2017, 53 (8), 6359-6376.

(14) Schaper, J. L.; Seher, W.; Nützmann, G.; Putschew, A.; Jekel, M.; Lewandowski, J. The Fate of Polar Trace Organic Compounds in the Hyporheic Zone. Water Res. 2018, 140, 158-166.

(15) Burke, V.; Greskowiak, J.; Asmuß, T.; Bremermann, R.; Taute, T.; Massmann, G. Temperature Dependent Redox Zonation and Attenuation of Wastewater-Derived Organic Micropollutants in the Hyporheic Zone. Sci. Total Environ. 2014, 482-483 (1), 53-61.

(16) Radke, M.; Maier, M. P. Lessons Learned from Water/Sediment-Testing of Pharmaceuticals. Water Res. 2014, 55, 63-73.

(17) Lewandowski, J.; Putschew, A.; Schwesig, D.; Neumann, C.; Radke, M. Fate of Organic Micropollutants in the Hyporheic Zone of a Eutrophic Lowland Stream: Results of a Preliminary Field Study. Sci. Total Environ. 2011, 409 (10), 1824-1835.

(18) Writer, J. H.; Antweiler, R. C.; Ferrer, I.; Ryan, J. N.; Thurman, E. M. In-Stream Attenuation of Neuro-Active Pharmaceuticals and Their Metabolites. Environ. Sci. Technol. 2013, 47 (17), 97819790.

(19) Li, Z.; Sobek, A.; Radke, M. Fate of Pharmaceuticals and Their Transformation Products in Four 

$5614-5621$.

(20) Kunkel, U.; Radke, M. Fate of Pharmaceuticals in Rivers: Deriving a Benchmark Dataset at Favorable Attenuation Conditions. Water Res. 2012, 46 (17), 5551-5565. Water Res. 2016, 102, 190-201.

(24) Zietzschmann, F.; Aschermann, G.; Jekel, M. Comparing and Modeling Organic Micro-Pollutant Adsorption onto Powdered Activated Carbon in Different Drinking Waters and WWTP Effluents.

(26) Schaider, L. A.; Ackerman, J. M.; Rudel, R. A. Septic Systems as Sources of Organic Wastewater Compounds in Domestic Drinking Water Wells in a Shallow Sand and Gravel Aquifer. Sci. Total Environ. 2016, 547, 470-481.

(27) Hellauer, K.; Karakurt, S.; Sperlich, A.; Burke, V.; Massmann, G.; Hübner, U.; Drewes, J. E. Establishing Sequential Managed Aquifer Recharge Technology (SMART) for Enhanced Removal 
of Trace Organic Chemicals: Experiences from Field Studies in Berlin, Germany. J. Hydrol. 2018, $563,1161-1168$.

(28) Bencala, K. E.; Walters, R. A. Simulation of Solute Transport in a Mountain Pool-and-Riffle

(29) Sudicky, E. A. The Laplace Transform Galerkin Technique: A Time-Continuous Finite Element Theory and Application to Mass Transport in Groundwater. Water Resour. Res. 1989, 25 (8), 1833-1846.

(30) de Hoog, F. R.; Knight, J. H.; Stokes, a. N. An Improved Method for Numerical Inversion of Laplace Transforms. SIAM J. Sci. Stat. Comput. 1982, 3 (3), 357-366.

(31) Vrugt, J. A.; Ter Braak, C. J. F. DREAM(D): An Adaptive Markov Chain Monte Carlo Simulation Algorithm to Solve Discrete, Noncontinuous, and Combinatorial Posterior Parameter Estimation Problems. Hydrol. Earth Syst. Sci. 2011, 15 (12), 3701-3713.

(32) Runkel, R. L. A New Metric for Determining the Importance of Transient Storage. J. North Am. Benthol. Soc. 2002, 21 (4), 529-543.

(33) Harvey, J. W.; Böhlke, J. K.; Voytek, M. A.; Scott, D.; Tobias, C. R. Hyporheic Zone Denitrification: Controls on Effective Reaction Depth and Contribution to Whole-Stream Mass Balance. Water Resour. Res. 2013, 49 (10), 6298-6316.

(34) Hart, D. R.; Mulholland, P. J.; Marzolf, E. R.; DeAngelis, D. L.; Hendricks, S. P. Relationships between Hydraulic Parameters in a Small Stream under Varying Flow and Seasonal Conditions. Hydrol. Process. 1999, 13 (10), 1497-1510.

(35) Malzone, J. M.; Anseeuw, S. K.; Lowry, C. S.; Allen-King, R. Temporal Hyporheic Zone Response to Water Table Fluctuations. Groundwater 2016, 54 (2), 274-285.

(36) Sui, Q.; Huang, J.; Deng, S.; Chen, W.; Yu, G. Seasonal Variation in the Occurrence and Removal of Pharmaceuticals and Personal Care Products in Different Biological Wastewater Treatment Processes. Environ. Sci. Technol. 2011, 45 (8), 3341-3348. 
(37) Nödler, K.; Hillebrand, O.; Idzik, K.; Strathmann, M.; Schiperski, F.; Zirlewagen, J.; Licha, T. Occurrence and Fate of the Angiotensin II Receptor Antagonist Transformation Product Valsartan Acid in the Water Cycle - A Comparative Study with Selected $\beta$-Blockers and the Persistent Anthropogenic Wastewater Indicators Carbamazepine and Acesulfame. Water Res. 2013, 47 (17), $6650-6659$.

(38) Acuña, V.; von Schiller, D.; García-Galán, M. J.; Rodríguez-Mozaz, S.; Corominas, L.; Petrovic, M.; Poch, M.; Barceló, D.; Sabater, S. Occurrence and In-Stream Attenuation of WastewaterDerived Pharmaceuticals in Iberian Rivers. Sci. Total Environ. 2015, 503-504, 133-141.

(39) Trautwein, C.; Kümmerer, K. Incomplete Aerobic Degradation of the Antidiabetic Drug Metformin and Identification of the Bacterial Dead-End Transformation Product Guanylurea. Chemosphere 2011, 85 (5), 765-773.

(40) Bradley, P. M.; Journey, C. A.; Button, D. T.; Carlisle, D. M.; Clark, J. M.; Mahler, B. J.; Nakagaki, N.; Qi, S. L.; Waite, I. R.; VanMetre, P. C. Metformin and Other Pharmaceuticals Widespread in Wadeable Streams of the Southeastern United States. Environ. Sci. Technol. Lett. 2016, 3 (6), 243-249.

(41) Trautwein, C.; Berset, J. D.; Wolschke, H.; Kümmerer, K. Occurrence of the Antidiabetic Drug Metformin and Its Ultimate Transformation Product Guanylurea in Several Compartments of the Aquatic Cycle. Environ. Int. 2014, 70, 203-212.

(42) Li, Z.; Sobek, A.; Radke, M. Flume Experiments to Investigate the Environmental Fate of Pharmaceuticals and Their Transformation Products in Streams. Environ. Sci. Technol. 2015, 49 (10), 6009-6017.

(43) Klaminder, J.; Brodin, T.; Sundelin, A.; Anderson, N. J.; Fahlman, J.; Jonsson, M.; Fick, J. LongTerm Persistence of an Anxiolytic Drug (Oxazepam) in a Large Freshwater Lake. 2015.

(44) Reemtsma, T.; Miehe, U.; Duennbier, U.; Jekel, M. Polar Pollutants in Municipal Wastewater and the Water Cycle: Occurrence and Removal of Benzotriazoles. Water Res. 2010, 44 (2), 596-604. 
(45) Henning, N.; Kunkel, U.; Wick, A.; Ternes, T. A. Biotransformation of Gabapentin in Surface Water Matrices under Different Redox Conditions and the Occurrence of One Major TP in the Aquatic Environment. Water Res. 2018, 137, 290-300.

(46) Hellauer, K.; Mergel, D.; Ruhl, A. S.; Filter, J.; Hübner, U.; Jekel, M.; Drewes, J. E. Advancing Sequential Managed Aquifer Recharge Technology (SMART) Using Different Intermediate Oxidation Processes. Water (Switzerland) 2017, 9 (221), 1-14.

(47) MacKay, A. A.; Vasudevan, D. Polyfunctional Ionogenic Compound Sorption: Challenges and New Approaches to Advance Predictive Models. Environ. Sci. Technol. 2012, 46 (17), 9209-9223.

(48) Huntscha, S.; Rodriguez Velosa, D. M.; Schroth, M. H.; Hollender, J. Degradation of Polar Organic Micropollutants during Riverbank Filtration: Complementary Results from Spatiotemporal Sampling and Push-Pull Tests. Environ. Sci. Technol. 2013, 47 (20), 11512-11521.

(49) Tülp, H. C.; Fenner, K.; Schwarzenbach, R. P.; Goss, K. U. PH-Dependent Sorption of Acidic Organic Chemicals to Soil Organic Matter. Environ. Sci. Technol. 2009, 43 (24), 9189-9195.

(50) Schaffer, M.; Boxberger, N.; Börnick, H.; Licha, T.; Worch, E. Sorption Influenced Transport of Ionizable Pharmaceuticals onto a Natural Sandy Aquifer Sediment at Different PH. Chemosphere 2012, $87(5), 513-520$.

(51) Briones, R. M.; Sarmah, A. K. Insight into the Sorption Mechanism of Metformin and Its Transformation Product Guanylurea in Pastoral Soils and Model Sorbents. Sci. Total Environ. 2018, 645, 1323-1333.

(52) Schaffer, M.; Börnick, H.; Nödler, K.; Licha, T.; Worch, E. Role of Cation Exchange Processes on the Sorption Influenced Transport of Cationic $\beta$-Blockers in Aquifer Sediments. Water Res. 2012, 46 (17), 5472-5482.

(53) Reinhold, D.; Vishwanathan, S.; Park, J. J.; Oh, D.; Michael Saunders, F. Assessment of PlantDriven Removal of Emerging Organic Pollutants by Duckweed. Chemosphere 2010, 80 (7), 687692. 
607

608

609

610
(54) Gooseff, M. N.; LaNier, J.; Haggerty, R.; Kokkeler, K. Determining In-Channel (Dead Zone) Transient Storage by Comparing Solute Transport in a Bedrock Channel-Alluvial Channel Sequence, Oregon. Water Resour. Res. 2005, 41 (6), 1-7.

(55) Harvey, J. W.; Wagner, B. J.; Bencala, K. E. Evaluating the Reliability of the Stream Tracer Approach to Characterize Stream-Subsurface Water Exchange. Water Resour. Res. 1996, 32 (8), 2441-2451.

(56) Haggerty, R. Power-Law Residence Time Distribution in the Hyporheic Zone of a 2nd-Order Mountain Stream. Geophys. Res. Lett. 2002, 29 (13), 1640. 


\section{Supporting Information}

617 (1) Map of the field site showing sampling locations (Figure SI-01), description of sediment 618 characteristics, hyporheic and surface water temperatures during sampling campaigns (Figure SI-02), 619 WWTP discharge during the tracer experiments (Figure SI-03), stream stage during the wet season 620 experiments (Figure SI-04), porewater velocities in the HZ measured using active heat pulse sensing 621 (Table SI-01) and total dissolved iron, dissolved manganese and $\mathrm{NO}_{3}{ }^{-} \mathrm{N}$ concentrations in the $\mathrm{HZ}$ (Table 622 SI-02, Figure SI-05); (2) Additional information on TrOC analysis (Tables SI-03 \& 04); (3) Description of 623 the transient storage model, tracer breakthrough curves and posterior distribution of model parameters 624 (Figures SI-06-09); (4) Details on calculation of $\mathrm{L}_{s} / \mathrm{L}_{\mathrm{c}}$ and discussion of approach; (5) $\log \mathrm{D}_{\mathrm{ow}}$ and $\mathrm{pKa}$ 625 values of investigated TrOCs (Table SI-05); (6) Comparison of stable reference compounds (Figure SI626 10), mean concentrations of TrOCs, total dissolved iron and manganese and $\mathrm{NO}_{3}{ }^{-} \mathrm{N}$ at Site A (Table SI627 06), relative removal (\%) of TrOCs not significantly removed between Site A and B (Table SI-07), half628 lives and relative removal (\%) of TrOC in the HZ (Tables SI-08 \& 09) and molar concentration ratios of 629 PCs to their TPs (Figure SI-11).

630 


\section{Acknowledgements}

632 This project has been conducted within the Research Training Group 'Urban Water Interfaces (UWI)' 633 (Project N6 "Retention of chemical compounds in hyporheic reactors of urban freshwater systems", GRK 634 2032/1), which is funded by the German Research Foundation (DFG). This project has also received 635 funding from the European Union's Horizon 2020 research and innovation programme under grant 636 agreement No. 641939 (HypoTRAIN) and No. 734317 (HiFreq). Additional funding through the 637 Australia-Germany Joint Research Cooperation Scheme of Universities Australia and the German 638 Academic Exchange Service (DAAD, grant no. 57216806) provided support for fieldwork collaboration 639 between the research institutes. SA Water (Government of South Australia) is gratefully acknowledged for 640 providing information and data from the WWTP facility at Heathfield. The authors are grateful to Camille

641 Bouchez for interesting discussions. We thank three anonymous reviewers and the editor for comments 642 and discussion on earlier versions of this manuscript. 